(Prof. DR. E. MARCUS)

\title{
Ocorrência de Ephydatia crateriformis (Potts) na America do Sul
}

\author{
POR \\ Joåo de Paiva Carvalho \\ Estagiário voluntário \\ Com um mapa no texto e duas estampas
}

Monografia das esponjas dágua doce da America do Sul ainda não foi tentada, havendo apenas, em trabalhos clássicos e recentes, descrições avulsas. Da literatura esparsa menciono, como exemplos principais, as publicações de BOWERBANK (1863), CARTER (1881), POTTS (1887), HINDE (1888), AUSTEN (1897), WELTNER (1898), ANNANDALE (1909; 1910; 1911; 1915) e CORDERO (1923; 1925; 1928).

Entre os autores citados, alguns exploraram tambêm a fauna das Spongillidae brasileiras, sobretudo do norte do pais.

Sobreleva considerar, como estudos iniciais, os de BOWERBANK (I. c., p. 442), que encontrou seis espécies, naquele tempo novas, incluídas por êle no gênero $S p \circ n g i|| a$ :

Dezoito anos mais tarde, CARTER (I. c., p. 87), examinando material idêntico ao que BOWERBANK teve em mãos, colocou as espécies dêste autôr nos gêneros $M$ eye ni a (gregaria). Tubella (pau lula reticulata e recurvata) e Parmula (bate s $i$ e b row $n i$ ). Além disso introduziu o gênero $U r u g u$ a y a com - espécie U corallioides e descreveu Spongilla na vicella Meyenia anonima e Tubella spinata

Do gênero Ṕ a r u la do Norte do Brasil, figura, em vários compêndios limnológicos, p. e. no excelente de WESENBERG-LUND (1937, p. 24 f. 35) uma fotografia de $P$ b $r \circ w n$ em que se vê um ninho de vespas sôbre a esponja, que ficara fóra dágua. 
POTTS (I. c., p. 195) referindo-se à proveniência de $\mathrm{S} p$ o n g i I l a n t tens Carter diz: "Localidade desconhecida; provavelmente America do Sul" Na monografia dêsse autôr figuram espécies encontradas no Brasil, no Uruguai, na Guiana Britânica e na Bolívia.

Já naquela epoca eram conhecidas cerca de 15 espécies sulamericanas, das quais 10 provinham do Amazonas. Cincoenta anos mais tarde ARNDT (1936, p. 13) indica o número de 27 espécies (31 formas) sulamericanas, sento uma fossil.

ANNANDALE (1910, p. 401-406) refere-se a exemplares de $S$ p o n.g il i a do lago Titicaca; LUTZ \& MACHADO (1915, p. 49) assinalam esponjas dos rios Carinhanha e Grande, afluentes do rio São Francisco; CORDEIRO (1923, p. 134) estuda duas Spongillidae de Santa Ana (Misiones) e Uruguaiana; ARNDT (1930, p. 48-49) refere-se a $P$ a $r m$ u la b r o w n i do Amazonas; OLD (1932, p. 452), quando compara $\mathrm{H}$ e te $\mathrm{r}$ o $\mathrm{m}$ e y e $\mathrm{n} \mathrm{i}$ a i n s ig n is Weltner, com $H$ re pe n s de Michigan, diz que a primeira espécie ocorre somente no Brasil.

CORDEIRO colecionou esponjas dágua doce em diversas localidades brasileiras. Não sei se além dos trabalhos dêsse autôr, acima citados, existem referências às espécies colecionadas no Estado de São Paulo.

Cumpre-me agradecer ao Sr. Prof. Dr. WALTER ARNDT, do Museu Zoológico de Berlim, a solicitude com que atendeu a diversos pedidos de esclarecimentos que the dirigi, bem como ao Sr. Prof. Dr. ERNESTO MARCUS e à sua Exma. Esposa, Snra. Da. EVELINE DU BOIS-REYMOND MARCUS, o consideravel auxílio que me foi dispensado na confecção do presente trabalho.

\section{Material e métodos}

Ao realizar estudos relativos à biologia da Manjuba ( $A, n c h$ o $v i a$ sp.) na região do rio Ribeira de lguape, durante o mês de Janeiro de 1941, por ocasião de um dos exames a que submeti a flora marginal e a vegetação submersa do citado rio, tive o ensejo de encontrar uma esponja dágua doce que crescia ao redor da haste duma planta aquática comum naquela região ( $E$ | o d e a sp.).

O primeiro fragmento colhido representa uma colónia em formação (Fig. I), e, no mesmo local, encontrei tambêm a colónia mais desenvolvida da Fig. 2, acompanhada de diversas outras menores.

O material achava-se em recanto remançoso, porém, de águas bem arejadas, da lagôa denominada "Pastinho" situada à margem direita do 
rio Ribeira (Mapa I-a). O termômetro acusou temperatura de $31^{\circ} \mathrm{C}$. e - exame microscópico dágua revelou abundância de matéria orgânica em suspensão, além de riqueźa apreciavel em micro-crustáceos. Idênticas condições apresentavam-se na lagôa formada à margem esquerda do rio Jacupiranga (Mapa I-b).

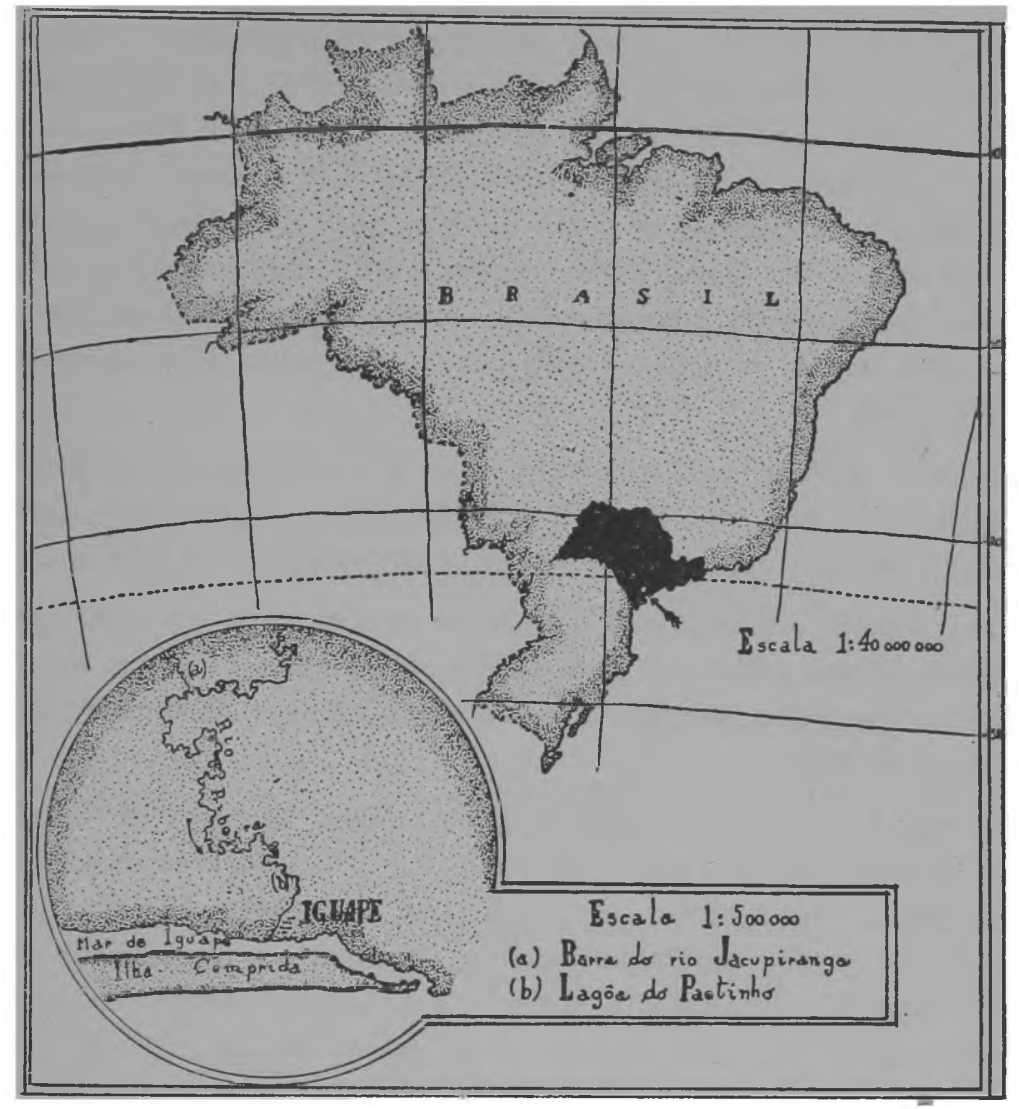

Mapa I

$\mathrm{Na}$ ocasião da primeira colheita, em Janeiro de 1941, as colónias encontravam-se desprovidas de gêmulas.

A 19 de Fevereiro do mesmo ano, graças aos esforços desenvolvidos pelo meu colega de trabalho, snr. FRANCISCO DE ANDRADE RAMOS, funcionário da Divisão de Proteção e Produção de Peixes e Animais Silvestres, do Departamento da Produção Animal, obtive grande quantidade de amostras, da mesma proveniência e em condições absolutamente idênticas às que haviam sido constatadas no mês anterior. Não somente êste material como o que foi enviado a 20 de Abril seguinte, da mesma localidade, 
achavam-se sem gêmulas e, assim, deixaram de fornecer maiores esclarecimentos.

Entre outros autôres, ANNANDALE (1911, p. 43), refere que na Europa, America do Norte e no Japão, a produção de gêmulas é constatada com a aproximação do inverno. Deliberei, por isso, realizar novas pesquizas a partir do mês de Junho. Servindo-me ainda dos valiosos préstimos do snr. AiNDRADE RAMOS, foi explorada uma lagôa, sem nome certo, situada nas proximidades da barra do rio Jacupiranga (Mapa I-b). Aí fiz a quarta coleta de amostras, em data de 20 de Junho. O material foi examinado e revelou a existência de pequenas vesículas de côr amarelo dourada, lembrando muito uma gotícula de ouro, sôbre a qual se houvesse lançado uma pincelada de verniz. Esses órgãos foram considerados como gêmulas em formação mas não apresentavam ainda vestígios de espículas ou amfidiscos. Apenas uma camada homogênea e opaca de arqueócitos distribuia-se no centro da gêmula.

Deliberei efetuar nova coleta no mês imediato, mesmo porque, dada a irregularidade das condições atmosféricas que caracterisaram $\circ$ ano de 1941, tudo indicava que convinha aguardar temperaturas mais baixas.

Particularmente interessante apresentou-se o material de Junho, no qual se encontrava uma colónia de Bryozoa Phylactolaemata, PI u m a t e I I a $f r u+i$ cos a Allm., pela primeira vez identificada na America do Sul (veja p. dêste Boletim).

No dia 22 de Julho, efetuei a quinta coleta, na barra do rio Jacupiranga. A temperatura dágua acusou $16,6^{\circ} \mathrm{C}$. Provavelmente devido à grande quantidade dágua contida no rio Ribeira $e$, consequêntemente, no leito do rio Jacupiranga, a vegetação aquática da lagôa por êle formada achavase meio submersa, circunstlância que dificultou sobremaneira a realização das coletas. Apesar disso, na flóra marginal, foram obtidas colónias bem desenvolvidas. Nêsse material foi possivel constatar a existência de gêmulas, que puderam ser pormenorizadamente examinadas.

A 17 de Agosto seguinte, no mesmo local, foi feita nova coleta de material, tambem provido de gêmulas. Amostras ulteriores foram obtidas ainda a 21 de Outubro, ocasião em que não mais constatei a presença de gêmulas.

Nas lagôas por mim visitadas, as colónias de espongiários nunca foram encontradas a profundidades maiores de $30 \mathrm{cms}$., nem em grandes quantidades. Foram raros os exemplares volumosos (como os da 5." coleta); frequentemente, as colónias desenvolviam-se sôbre raizes de plantas aquáticas. Isso concorda com as observações feitas por diversos autores, dizendo, p. e., 
BAILEY (West Point, Nova York), em resposta à consulta de BOWERBANK (1863, p. 443) : "As Spongillidae dos pequenos lagos desta região, raramente formam massas volumosas"

Aiguns fragmentos adêrentes a raizes de Eichhornia crassi $p$ e s (Aguapé), revelaram a existência de pequenas colónias em formação, nas quais foi possivel observar, durante dois dias, o movimento constante das correntes internas, através da transparência do epitélio pavimentoso. Viram-se transportadas pequenas partículas escuras, que circulavam do átrio cloacal ao conduto exhalante ou ósculo. Essas colónias foram mantidas viventes durante pouco mais de dois dias.

A minha técnica de fixação obedeceu às regras usuais. Na maceração destinada a facultar o exame das espículas, colocam-se fragmentos da esponja fresca em "Eau de Javelle" que, conforme a temperatura, deve ser trocada mais ou menos frequentemente. Tive bons resultados tambêm com a maceração em água e com o método aconselhado por OLD (1932, p. 440), baseado em concentrado frio de $\mathrm{HNO}_{3}$.

Para a clarificação das gêmulas, obtive bons resultados com a solução alcoólica de fenol aconselhada por CORDERO (1925).

\section{Notas sistemáticas}

O gênero Ephyda ti a de distribuição cosmopolita (ARNDT 1926, p. 357) e já verificado no Eocêno da Húngria (ibid., p. 346) foi introduzido na ciência por LAMOUROUX $(1816$, p. 2), referindo-se o nome a uma Náiada da mitologia grega. A posição das esponjas no reino animal ou vegetal ainda não se achava definida nessa época (LAMOUROUX I82I, p. 28). figurando, todavia, $E \mathrm{p}$ h y $d$ a $t i$ a, na última monografia de LAMOU. ROUX (1824, p. 47), como animal. Já o grande zoologo, que era JOHN ELLIS (1786, p. 182), tinha definido as esponjas como animais e as pesquisas de ROBERT EDMUND GRANT (1825 e seg) e JOHN FLEMING (1828, "A History of British Animals" Edinburgh) estabeleceram definitivamente a posição dos Porifera entre os animais (CARUS 1880, p. 565). Tal foi tomado na devida consideração no clássico manual de actinologia de BLAINVILLE (1834, p. 533-534), mas, na enciclopedia de OKEN (184I, p. 21I), muito espalhada naquele tempo, as esponjas límnicas e marinhas ainda foram tratadas como plantas, entre algas, liquens e musgos. JOHNSTON (1847. p. 433-434) contesta ainda na segunda edição da sua famosa História dos Zoófitos Britânicos a natureza animal das esponjas, destituidas de órgãos individuais, em oposição aos polipos dos Cnidaria, nêsse tempo tidos por órgãos 
dos "Polipeiros" e, além disso. sem as funções exibidas, geralmente, pelos animais.

A espécie atual ainda não foi verificada na America do Sul, e, por isso, não pude classificá-la com auxílio das publicações relativas às Spongillidae sulamericanas. Devo a identificação à excelente monografia das Spongillidae índicas (ANNANDALE 1911), onde a espécie foi incorporada (p. 351) no gênero $\mathrm{S} p$ ong ill a LAMARCK 1816. A sinonimia, reunida por ANNANDALE (i. c.), mostra que a espécie foi descrita por POTTS (1882) como Meyenia crateriformis. Visto, porém, que Meyenia CARTER (1881, p. 90) é sinônimo de $E p h$ y d a $t i$ a LMX. (ARNDT 1926, p. 35I), e a classificação de $c r$ a $t$ e $r$ i f o $r m$ is no gênero S p o ng i I l a "era pouco feliz" (carta do Prof. Dr. ARNDT, de 22 de Setembro de (941), o nome correto há de ser Ephyda ti a crate r if or m is (Potts).

A classificação das S p o n g i ll i d a e baseia-se, em grande parte, nas gêmulas. A configuração das colónias depende, como em outros animais sésseis, os Briozoos, de vários fatores mesológicos, de análise dificil, como tambêm do estado fisiológico e da idade das colónias. Assim, encontrou OLD (1932, p. 443) colónias ramificadas e compactas de S p o n g ill a l a custris umas ao lado das outras, em lagos e rios norteamericanos. Nêsses casos, evidentemente, não atuavam fatores ecológicos, no sentido de CARPENTER (1928): "as fórmas ramificadas ocorrem em lagos e o típo plano em rios; constituindo êste uma resposta às condições adversas, provocada pela rapidez da correnteza"

A diversidade morfológica que dificulta a determinação de colónias, mesmo amplamente desenvolvidas, mas, desprovidas de gêmulas, levou os pesquisadores a recorrer até a sinais químicos, manifestados, segùndo VAN TRIGT, pelo cheiro diferente de duas espécies comuns na Europa, mencionando ARNDT (1928, p. 80) êsse carater na chave para a determinação daquelas colónias das Spongillidae da Alemanha, cujas gêmulas não se acham desenvolvidas.

\section{Descrição de Ephydatia crateriformis (PotTs) forma arndti, forma nova}

As colónias, quando aderentes a ramos de vegetação, são relativamente frágeis, transparentes e digitiformes. Em outros substratos, são mais robustas e volumosas. A massa irregular dos exemplares robustos é recober. ta por membrana tênue, mas nítida, em que se destacam os póros. Retirada dágua, a esponja parece envolta em película fina. 
As colónias adêrentes a filamentos de algas, a raízes de Eichhorn i a crass i p es (Aguapé) ou a ramos de capins marginais, assumem, por vezes, o aspeto de corpos robustos que lembram a configuração de Pa r m u l a brow n i do Amazonas.

As espículas podem ser divididas em tres tipos, a saber: I. No parênquima: a) "tornota" providas de espinhos dispersos pelo corpo, levemente encurvadas, com canal central de uma extremidade à outra; b) "óxea" estreiłas, lisas e retas, tambêm com canal central nítido; c) "tylostyla" retas, espinhosas, com canal central idêntico às demais.

II. Na gêmula: sanidaster" fortemente espinhosas, retas ou levemente encurvadas.

Algumas espículas periféricas da gêmula, colocadas simetricamente em sentido horizontal e tangencial, bem como outras, irregular e centralmente dispostas, possuem a parte mediana quasi lisa ou são providas de pequenas pontas espinhosas tênues. Outras são espinhosas de cima a baixo, tendo algumas as pontas recurvadas (Fig. 5).

As espículas "tornotas" são levemente encurvadas e espinhosas, existindo algumas que em uma das extremidades formam ângulo (Fig. 8).

As "óxeas" são mais delicadas, lisas e, em ambas as extremidades, terminam em pontas aguçadas (Fig. 6).

As "tylostylas" em forma de bastão, são espinhosas e robustas, com uma das extremidades obtusa e a outra pontuda (Fig. 7).

MEDIDAS DAS ESPICULAS (em microns)

\begin{tabular}{|c|c|c|c|c|}
\hline \multicolumn{5}{|c|}{$\begin{array}{c}\text { ESPICULAS DO PARENQUIMA } \\
\text { (Dez amostras) }\end{array}$} \\
\hline \multicolumn{3}{|c|}{ Tornota } & Óxea & Tylostyla \\
\hline I & - & 283,5 & 240.7 & 193,6 \\
\hline 2 & - & 275,4 & 250,6 & 195,4 \\
\hline 3 & - & 267,3 & 265,5 & 200,7 \\
\hline 4 & - & 251,1 & 280,4 & 200.9 \\
\hline 5 & - & 267,3 & 275,8 & 200.4 \\
\hline 6 & - & 210,6 & 280,6 & 200,6 \\
\hline 7 & - & 291,6 & 280.9 & 190,8 \\
\hline 8 & - & 271,3 & 280.9 & 190,7 \\
\hline 9 & - & 299,7 & 275,8 & 190,7 \\
\hline 10 & - & 275,4 & 278.3 & 195.5 \\
\hline
\end{tabular}

\begin{tabular}{|c}
$\begin{array}{c}\text { ESPICULAS DAS GEMULAS } \\
\text { (Dez amostras) }\end{array}$ \\
\hline $1-66,6$ a 68,8 \\
$2-64,8$ a 66,6 \\
$3-55,5$ a 56,7 \\
$4-56,7$ a 59,2 \\
$5-64,8$ a 66,6 \\
$6-79,9$ a 80,0 \\
$7-64,8$ a 66,6 \\
$8-60,7$ a 62,9 \\
$9-56,7$ a 62,9 \\
$10-64,8$ a 66,6 \\
\hline
\end{tabular}


MEDIDAS DAS GEMULAS (em microns)

\begin{tabular}{|c|c|c|}
\hline \multicolumn{3}{|c|}{ (Dez amostras) } \\
\hline & Diâmetro interno & Total \\
\hline 1 & 258 & 378 \\
\hline 2 & 260 & 381 \\
\hline 3 & 258 & 379 \\
\hline 4 & 260 & 380 \\
\hline 5 & 261 & 380 \\
\hline 6 & 261 & 380 \\
\hline 7 & 260 & 380 \\
\hline 8 & 260 & 380 \\
\hline 9 & 258 & 382 \\
\hline 10 & 260 & 381 \\
\hline
\end{tabular}

As gêmulas possuem configuração globular (Fig. 3). De colorido amarelo dourado, são dotadas de epiderme bem visivel, destacando-se a linha escura da membrana externa e a camada central.

O tubo foraminal (Fig. 4), mais evidente nas gêmulas em formação, é cilíndrico, de tamanho médio e mais alargado na base. A extremidade do orifício, em geral, não ultrapassa a margem limitada pela corôa de espículas dispostas tangencial e horizontalmente na camada externa.

Algumas gêmulas apresentam conformação singular, pois, possuem tubo foramina! duplo.

Foi especialmente o exame das espículas das gêmulas que me levou à classificação definitiva do material do rio Ribeira de lguape. A passagem correspondente de ANNANDALE (1911, p. 84) indíca: "Espículas das gêmulas muitas vezes livres no parênquina, cilíndricas, delgadas e de comprimento variavel nos vários espécimes de esponjas. São retas ou quasi retas; em geral, possuem em cada extremidade um círculo irregular de espinhos fortes, direitos ou encurvados que lembra rótula rudimentar. Além disso, ocorrem no eixo da espícula gemular espinhos curtos e retos. As vezes são as espículas gêmulares desprovidas de rótulas e, nêsses casos, ou são truncadas ou terminam com ponta aguda"

Os vestígios de tal rótula rudimentar nas espículas gemulares do meu material de Junho, cujas gêmulas se acharam ainda em formação, aconsetharam-me a aguardar $\circ$ recebimento de novas amostras. Colhidas estas a 17 de Agosto, na barra do rio Jacupiranga, verifiquei a constância dos caracteres das espículas gemulares.

Em comparação com as espículas gemulares da forma típica de $E \mathrm{ph}$ y datia crateriform is (Potts), bem lustradas por GEE (1932, p. 
525-543 f. 3 b) e ARNDT (1931, p. 557 f. 3), apresentam-se as do meu material notavelmente robustas e mais entroncadas.

Por isso, segui o consetho do Prof. ARNDT, considerando os espécimes do Sul do Estado de São Paulo como representantes duma forma peculiar, que tenho o prazer de dedicar ao famoso pesquisador do Museu de Berlim, Prof. Dr. WALTER ARNDT.

\section{Notas zoogeográficas}

A ocorrência de Ephydatia crateriformis (Potts), na América do Norte, foi assinalada por OLD (1932, p. 470). As duas localidades mais aproximadas à América do Sul são: I) Dzadz Aguada, $10 \mathrm{Km}$., a suleste de Chichen Itza, no Yucatan (OLD 1936, p. 29); 2) Rio Colorado, perto de Lerdo. Sonora (México), 59 milhas do forte Yuma, na Califórnia (ARNDT 1933, p. 17-26 t. 1-2).

Outros lugares de achado norteamericanos são: Maryland, Pennsylvania, New York, Ohio, Indiana, Hinois, Michigan e Wisconsin.

A espécie ocorre, além disso, no Japão, na China, nas llhas Filipinas e nas Indias Orientais.

$\mathrm{Na}$ Europa Ephydatia crateriformis não foi verificado (ARNDT 1926, p. 350), baseando-se a indicação contrária, relativa à Irlanda, evidentemente em classificação errônea (OLD 1932, p. 472).

\section{Fauna acompanhadora}

O exame das colónias revelou a existência de diversos animais que nelas se encontravam, procurando alimento ou abrigo. Seria tarefa de trabalho especial pesquisar os componentes da fauna acompanhadora, tanto sistemática, quanto biologioamente, nas várias épocas do ano. Como enumeração preliminar limito-me, por enquanto, a assinalar os elementos principais de dita fauna:

BRYOZOA. Plumatella fruticosa Allm., encontrada em Junho.

NEUROPTERA. Larvas de Sisyra (Fig. 9-10), conhecidas inimigas e habitantes das Spongillidae (ANNANDALE 1911, p. 49; OLD 1933, p. 670), foram observadạs em quasi todas as colónias e, sobretudo, nas do mês de Junho. Essas larvas são semelhante às malaias desenhadas por ESBEN-PETERSEN (1933 p. 628 f. I e 2). As figuras de espécimes europeus de STITZ (1931, f. 61) e HEYMONS (1909, f. 42), sobretudo as de STITZ, aproximam-se mais ainda dos exemplares do rio Ribeira. 
DIPTERA. Foram encontradas inúmeras larvas de Chironomidae.

COPEPODA. Figuraram exemplares de Cyclops sp., em relativa abundância.

OLIGOCHAETA. As várias Naididae que povoam as esponjas, acham-se, atualmente, em estudo no Departamento de Zoologia.

\section{Resumo}

Trata o presente trabalho de um espongiário encontrado no rio Ribeira de lguape, tanto na lagôa denominada de "Pastinho" como de outra, sem nome certo, situada a montante, próximo à embocadura do rio Jacupiranga.

Na localidade mais exposta à corrente e rica em substâncias alimentícias (Mapa 1-b) houve colónias massiças, assaz volumosas; nas águas menos ricas em matéria orgânica (Mapa I-a) e, ao mesmo tempo, mais calmas, as colónias cresceram, em geral, digitiformemente.

Ambas as regiões sofrem diariamente a influência das marés, que se faz sentir até pouco acima da barra do citado rio. A espécie deve, pois, ser considerada como de água doce e salôbra.

Dos achados mensalmente realizados de Janeiro (1941) a Outubro, as gêmulas apareceram somente no período de Junho e Agosto.

E. crateriformis não foi até agora verificada na América do Sul, sendo as duas localidades mais próximas, a península de Yucatan e a zona fronteiriça entre o México e a Califórnia.

Confrontando as espículas das gêmulas do material atual com as da forma típica de Ephydatia crateriformis (Potts), verifiquei entroncamento ou robustez não presente na forma típica. A conselho do Prof. Dr. WALTER ARNDT (Berlin), considerei o dito carater como sinal distintivo duma nova forma, E. crateriformis forma arndti, denominada em homenagem àquele pesquizador.

\section{Abstract}

In the South of the State of São Paulo Ephydatia craterifor$\mathrm{m}$ is (Potts) was found in the river Ribeira de Iguape (Map on p. 269). In one of the two localities where the sponges were obtained the water was richer in organic matter and was more exposed to the current than in the other. In the first place the sponges grow massively (Fig. 2), forming rather bulky masses, in the second the colonies are finger-like. Both places are still in the region of the tides, and their water sometimes becomes a little 
brackish. In the period from january to october 1941 gemmulae appeared only from june to august.

The species has not yet been verified in South America; the nearest findings are Yucatan (OLD 1936) and Mexico near the californian frontier (ARNDT 1933).

The more robust spicules of the gemmulae caracterize the present. material as a new form, forma a $r \mathrm{ndti}$ named in honour of the famous spongiolist, Dr. Walter Arndt of the Zoological Museum in Berlin, who has been kind enough to revise my classification.

Larvae of Sisyra (Fig. 9-10) occur in the sponges as well as larvae of Chironomidae, Copepods of the genus $\mathrm{Cyclops}$ and various Oligochaeta of the family Naididae. Also zoaria of Polyzoa (Bryozoa) Phylactolaemata were found, which Dr. Marcus tentatively identified with Plumatella fruticosa Allm.

\section{Literatura}

ANNANDALE, N. 1909, Fresh-water sponges in the collection of the U. S. National Museum. Part 2. Specimens from North and South America. Proc. U. S. Nat. Mus. v. 37, p. 401-406. Washington.

- 1911. The Fauna of British India, including Ceylon and Burma. Freshwater Sponges, Hydroids and Polyzoa. Freshwater Sponges (Spongillidae), p. 25-126, 24I-245, f. 1-26, 48 t. 1-2. London (Taylor and Francis).

- 1913, An Account of the Sponges of the Lake Tiberias, etc. Journ. Asiat. Soc. Bengal n. ser. v. 9 n. 1, p. 57-88 t. 2-5. Calcutta.

ARNDT, W. 1926, Die Spongillidenfauna Europas. Arch. Hydrobiol. v. 17, p. 337-365. Stuttgart.

- 1928, Porifera, Schwämme, Spongien. F. Dahl, Tierw. Deutschl. pars 4, 96 p. 110 f. Jena (G. Fischer).

- 1930, Lehmwespenansiedlung auf einem brasilianischen Süsswasserschwamm. Sitz. Ber. Ges. Naturf. Freunde Berlin 1930, p. 48-49. Berlin.

- 1931, Die Süsswasserschwämme der Deutschen Limnologischen Sunda-Expedition. Arch. Hydrobiol. Suppl. v. 9, p. 549-584. Stuttgart.

- 1933. Zur Kenntnis der Süsswasserschwammfauna Mexikos. Fragmenta Faunistica Mus. Zool. Polon. v. 2 n. 5, p. 17-26 t. 1-2. Warszawa.

- 1936, Die von Dr. A. Monard in Angola gesammelten Süsswasserschwämme. Arquiv. Mus. Bocage v. 7, p. 7-35. Lisbôa.

AUSTEN, E. 1897, Notes on a recent zoological expedition to the Lower Amazon. Proc. Zool. Soc. London 1896, p. 768-779. London.

BLAINVILLE, H. M. D. de 1834, Manuel d'Actinologie ou de Zoophytologie. VIII + 695 p. 100 t. Paris.

BOWERBANK, S. 1863, A Monograph of the Spongillidae. Proc. Zool. Sxc. London 1863, p. 440-472 t. 38. London. 
CARTER, E. H. 188I, History and Classification of the known Species of Spongilla. Ann. Mag. Nat. Hist. ser. 5 v. 7, p. 77-107 t. 5-6. London.

CARUS, V. 1880, Histoire de la Zoologie (Traduction française). VIII + 623 p. Paris. CORDERO, E. H. 1923, Dos esponjas de agua dulce (Spongillidae) de la America del Sur. Physis v. 7, p. 134. Buenos Aires.

- 1925, Dos Esponjas de agua dulce Sudamericanas. Commun. Mus. nac. Buenos Aires v. 2 (1924). p. 113-124. Buenos Aires.

- 1928, La variabilidad de la longitud de las espículas esqueléticas de dos especies. de esponjas de agua dulce del género Uruguaya. Physis v. 9, p. 259-260. Buenos Aires.

ELLIS, J. 1786, The Natural History of many curious and uncommon Zoophytes, etc. Systematically arranged and described by D. Solander. XII + 208 p. 63 t. London.

ESBEN-PETERSEN, P. 1933. Neuroptera der Deutschen Limnologischen Sunda-Expedition. Arch. Hydrobiol. Suppl. v. II, p. 625-630. Stuttgart.

GEE, N. G. 1932, More Philippine Islands Fresh-water Sponges. Philippine Journ. Sci. v. 48, p. 525-543. Manila.

GRANT, R. E. 1825, Observations and Experiments on the Structure and Functions of the Sponge. Edinb. Philos. Journ. v. 13, p. 94-107, 343-346. Edinburgh Inão visto por mim; citado segundo J. V. Carus \& W. Engelmann, Biblioteca Zoologica v. I. p. 312. Leipzig 18611 .

HEYMONS, R. \& H. 1909. Neuroptera. A. Brauer, Süsswasserfauna Deutschl. fasc. 7. p. 17-26. Jena (G. Fischer).

HINDE, G. J. 1888, On some New Species of Uruguaya Carter with rémarks on the Genus. Ann. Mag. Nat. Hist. ser. 6 v. 2, p. $1-12$ t. 4. London.

JOHNSTON, G. 1847, A History of the British Zoophytes. 2." ed. v. I, XVI +488 p. London.

LAMOUROUX, J. V. F. 1816, Histoire des Polypiers Coralligènes flexibles, vulgairement nommés Zoophytes. LXXXIV + 560 p. 19 t. Caen.

- 1821, Exposition méthodique des genres de l'ordre des Polypiers, etc. VIII + 115 p. 84 t. Paris.

- 1824. Corallina, or a classical arrangement of flexible coralline Polypidoms, selected from the French, etc. p. I-XXVI, 27-284 t. 1-19. London.

LUTZ, A. \& MACHADO, A. 1915, Viajem pelo rio S. Francisco e por alguns dos seus afluentes entre Piraporo e Joazeiro. Mem. Inst. Oswaldo Cruz v. 7, p. 5-49 †. 1-18. Rio de Janeiro.

MARTINEZ, L. 1940, Nota bioestadistica acerca de los anfidiscos de las esponjas Ephydatia fluviatilis mexicano y Heteromeyenia repens spinurosa del lago Xochimilco. An. Inst. Mexico v. 11 n.' 1. p. 191-196. Mexico.

OLD, M. C. 1932, Taxonomy and Distribution of the fresh-water Sponges (Spongillidae) of Michigan. Papers Mich. Sci. Arts \& Letters v. 15, p. 439-476. Ann Arbor.

- 1933. Contribution to the Biology of Fresh-water Sponges (Spongillidae). Papers Mich. Sci. Arts \& Letters v. 17, p. 663-679. Ann Arbor.

- 1936, Yucatan Fresh-water Sponges. The Cenotes of Yucatan. Carnegie Inst. Washingt. Publ. n. 457, p. 29-31. Washington, D. C. 
OKEN, L. V. 1841, Allgemeine Nathurgeschichte, etc. v. 3 pars I' (Botânica v. 2 pars 1), 702 p. Stuttgart.

POTTS, E. 1887, Freshwater Sponges: a Monograph. Proc. Acad. Nat. Sci. Philadelphia 1887. p. 1-4, 157-279 t. 5-12. Philadelphia, PA.

STITZ, H. 1931, Planipennia. P. Schulze, Biol. Tiere Deutschl. fasc. 35, p. 67-304 f. I-334. Berlin (Gebr. Borntraeger).

WELTNER, W. 1898, Ephydatia ramsayi (Haswell) forma talaensis aus Argentinien. Boll. Mus. Torino v. 13, 3 p. Torino.

WESENBERG-LUND, C. 1937, Ferskvandsfaunaen biologisk belyst. Invertebrata v. I, VI + 414 p. 526 f. 12 f. (Spongillidae: p. 3-28) Köbenhavn (Gyldendalske Boghandel) 


\section{ESTAMPA I}

1 - Ephydatia crateriformis (Potts) forma arndti: colónia em formação.

2 - Ephydatia crateriförmis (Potts) forma arndti. colónia mais desenvolvida.

3 - Gêmula de E. crateriformis (Potts) forma arndti.

4 - Dois tipos de tubo foraminal de E. crateriformis (Potts). forma arndti

5 - Espículas "sanidaster" das gêmulas.

6 - Espícula "óxea" do parênquima.

7 - Espícula "tylostyla" do parênquima.

8 - Espículas "tornota" do parênquima. 
JOÃO DE PAIVA CARVALHO - Ocorrência de Ephydatia crateriformis (Potts) na America do Sul

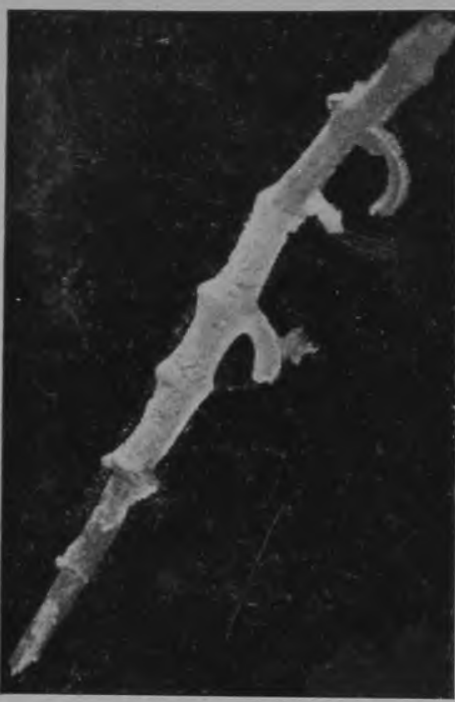

Fig. I

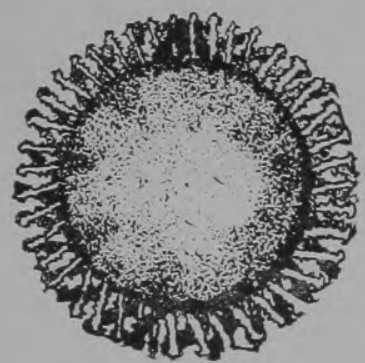

Fig. 3

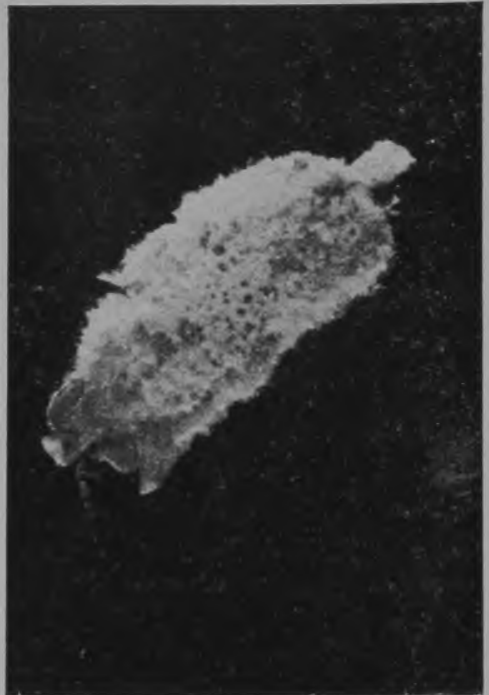

Fig. 2

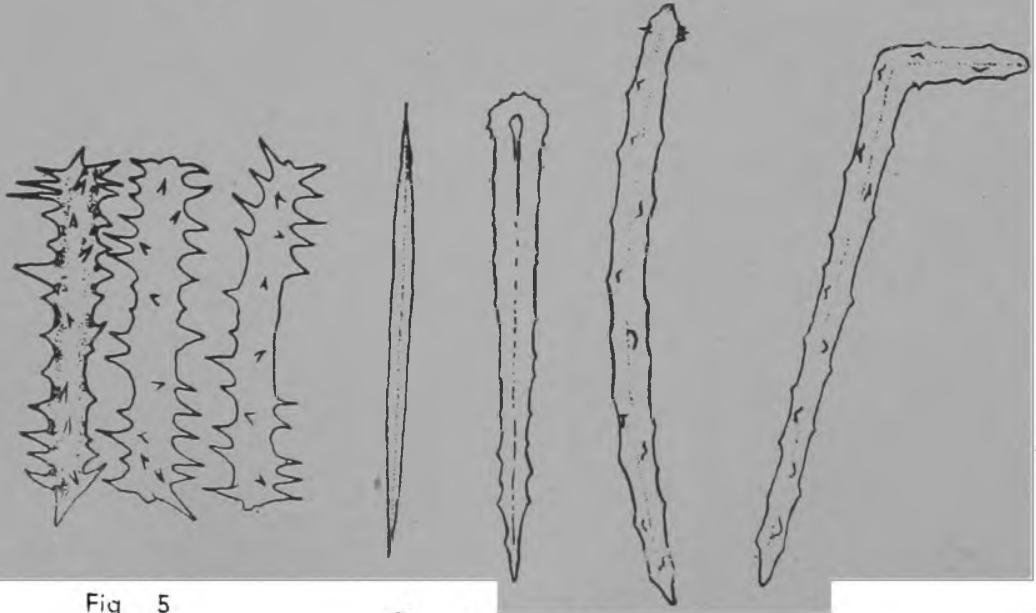

Fig. 6

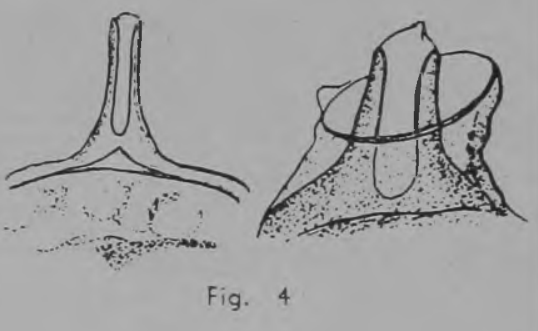

Fig. 7

Fig. 8 
ESTAMPA ॥

9 - Larva de Sisyra Fáse jovem.

10 - Larva de Sisyra Fáse mais desenvolvida. 
JOÃO DE PAIVA CARVALHO - Ocorrência de Ephydatia crateriformis (Potts). na America do Sul

ESTAMPA \#

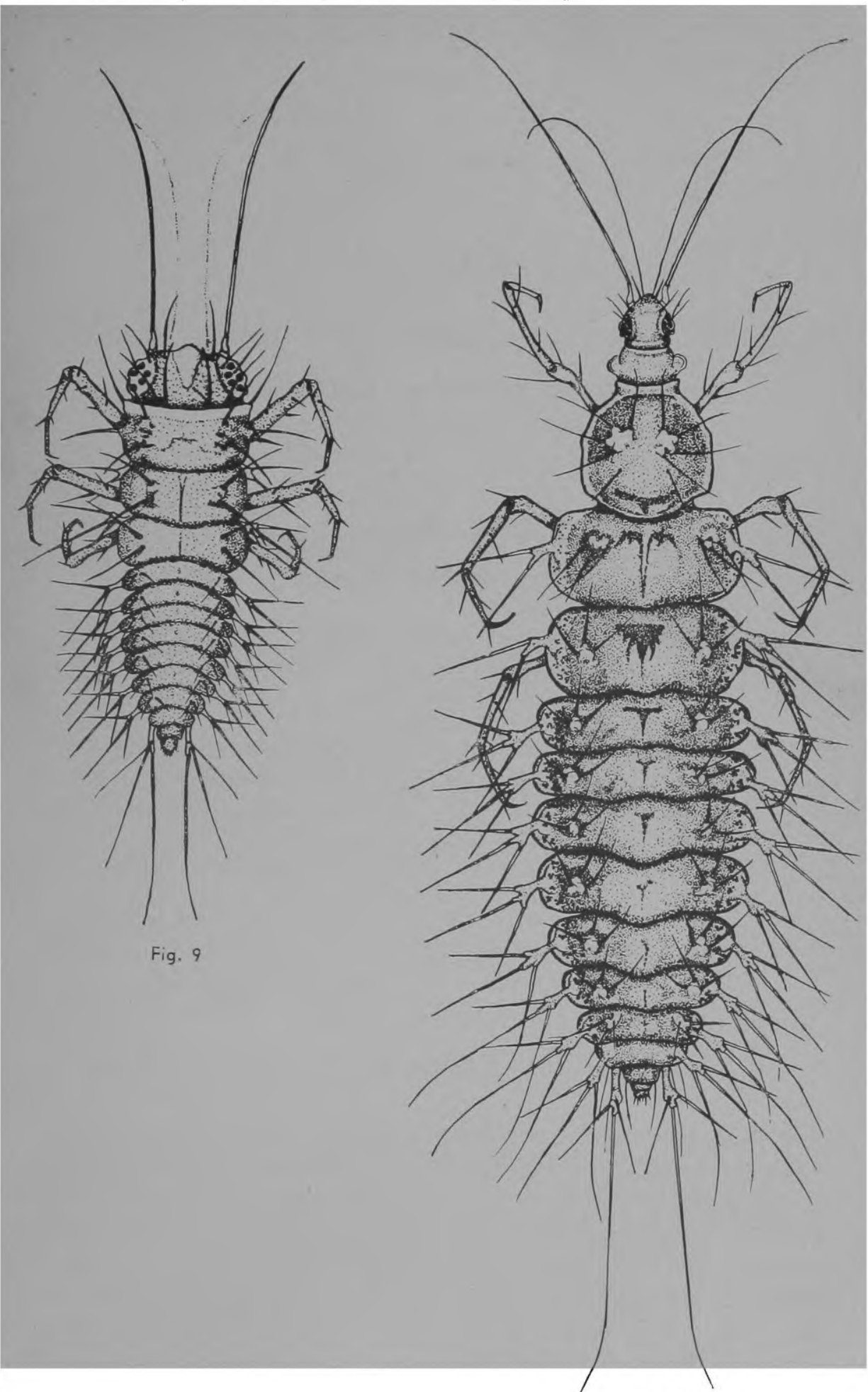

Fig. 10 